How can disciplines that are commonly regarded as culturally neutral be taught in ways that connect technical content with social and cultural issues?

\title{
Infusing Mathematics with Culture: Teaching Technical Subjects for Social Justice
}

\section{Dale Winter}

Quantitative methods and logical reasoning provide tools for making informed judgments about situations encountered in everyday life-the arena of cultural and social phenomena. Despite this, academic encounters with social and cultural issues are rare in the lecture halls and laboratories of STEM (science, technology, engineering, and mathematics) disciplines (Miller, 2005), the disciplines that traditionally emphasize training in quantitative analyses and logical thinking (English and Halford, 1995).

For more than twenty years the undergraduate mathematics teaching community has conducted a deep conversation concerning the pedagogies appropriate for introductory mathematics courses, including college algebra, precalculus, and calculus (Ganter, 2000, 2001). Fueling this ongoing discussion has been the recognition that students' failure to "acquire a deep understanding of the material they are supposed to learn in their [mathematics] courses" (Graesser, Person, and Hu, 2002, p. 33) is still unacceptably common (Bookman and Friedman, 1994; Selden, Mason, and Selden, 1989; Smith, 1998).

This conversation has produced changes in the pedagogy of many mathematics courses (Hurley, Koehn, and Ganter, 1999; Lutzer, Maxwell, and Rodi, 2002), including increased use of cooperative learning and technology to promote learning. Recognizing the value of student interest as a

\section{(WILEY}

\section{InterScience}


resource for learning (Schiefele and Csikszentmihalyi, 1995), many instructors have highlighted the applicability and usefulness of mathematical techniques for solving problems in the world outside the classroom (see Alper, Fendel, Fraser, and Resek, 1996; De Bock and others, 2003; Forman and Steen, 2000; Pollack, 1978; Walkerdine, 1988). One rationale for integrating social and cultural learning with traditional STEM learning is to use undergraduates' enthusiasm for social and political issues (National Survey of Student Engagement, 2004) as an engine to drive more abstract and conceptual mathematical learning (Carter and Brickhouse, 1989; Nix, Ryan, Manly, and Deci, 1999; Zoller, 1990).

\section{A Model for Integrating Social and Cultural Issues into STEM Learning}

The fundamental goal of any STEM course must be to involve students in the acquisition and mastery of the knowledge, skills, and perspectives of a technical discipline (Hauser, 2006). My model (see Figure 12.1) intertwines the technical learning characteristic of STEM disciplines with experiences and information to allow students to make better sense of some of the challenges and problems faced by other peoples and other cultures. This approach presents some immediate instructional challenges. For example, the understandable drive to emphasize STEM content in a STEM course might lead to a trivialization of the social and cultural studies aspects of the course (Cooper, 1992; Pollack, 1978). Wiest (2002) notes that incorporating cultural and social content into mathematics instruction might well be considered "inappropriate ... if the [cultural] content is merely grafted onto a topic ... or treated superficially" (p. 49). To help to avoid trivialization, I have followed one of the models suggested by Wiest, studying social and cultural issues using precalculus mathematical concepts as a tool.

In practical terms, implementation of this approach involved introducing sociocultural phenomena through collections of readings (including photographs and maps where appropriate), short video clips illustrating key aspects of each situation, and activities or games that the students would engage with as preparation for their mathematical work. When the students had become acquainted with the social situation, a problem or question would be posed to them and a structured worksheet provided to guide students through the intellectual process of developing mathematical tools to make better sense of the social problem (see Figure 12.1).

Students' newly acquired knowledge of social problems and cultural ideas was intertwined with mathematical ideas they could apply to represent salient features of the situation mathematically, reformulate the problem in mathematical terms (see Figure 12.1), and use the mathematical ideas that they had learned to solve the problem.

Upon solving the mathematical version of the problems, students completed a cycle of learning by interpreting the meaning of their mathemati- 


\section{Figure 12.1. Interplay Between Mathematical, Social, and Cultural Learning.}

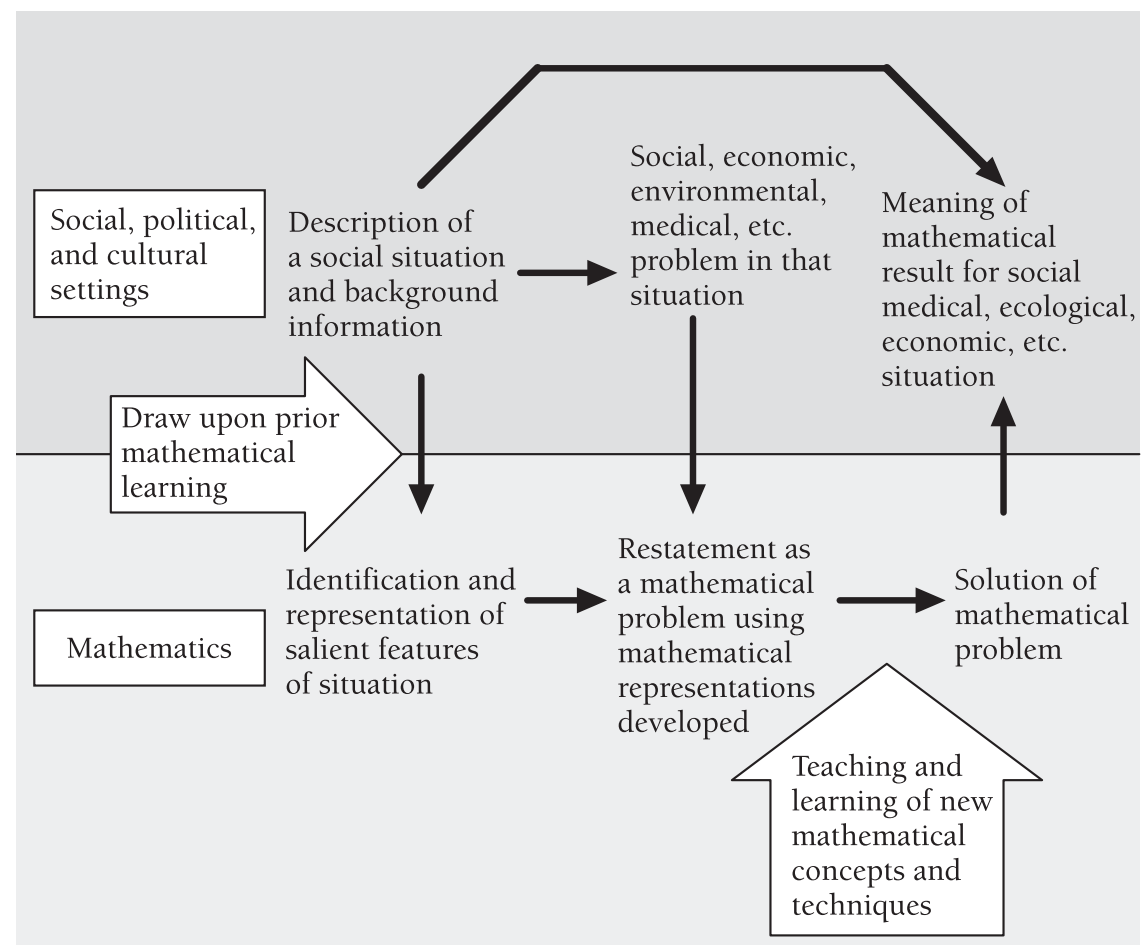

cal solution in the context that they had begun with, often leading to discussion of the broader implications of their solution. This was particularly the case in controversial examples such as deciding on the best course of action for using limited public funds in the fight against HIV/AIDS in Uganda.

To illustrate the learning activities that were used, an example follows. (A complete list of the topics and the mathematical concepts involved is provided in Table 12.1.)

\section{Native Peoples' Rights and Fresh Water in Botswana}

This learning activity used the context of water rights in Botswana as motivation for the mathematical concepts of piecewise defined functions, domain, and range.

Students began this activity with a short, informal general knowledge quiz about countries in sub-Saharan Africa. The answers to many of these 
Table 12.1. Topics Covered Using Enhanced Learning Activities During the Course

Social Problem

Racial and gender imbalance in new HIV infection rates in the United States

Political corruption and economic development in Africa, Southeast Asia, Europe, and South America

Climate change in Zimbabwe and the impact on agriculture

Water security and native peoples' rights in Botswana

Ancestral lands and petroleum resources: the Uighur minority and redheaded mummies of western China

Estimating the impact of chemical fertilizers in sub-Saharan Africa

The global disease burden of malaria

The cost of providing ARV medications in Uganda
Mathematical Concepts Involved

Comprehension and integration of information presented in numerical, algebraic, graphical, and verbal formats

Manipulation and analysis of numerical data

Graphing data points

Finding patterns

Linear regression

Interpretation of the slope and intercept of a linear function

Recognizing and creating linear functions Graphing linear functions

Finding intersection points

Interpreting the practical meaning of intersection points

Domain and range of a function

Functions defined in pieces

Finding intersection points

Interpreting the practical meaning of intersection points

Exponential functions

Half-lives and radioactive decay

Setting up and solving exponential functions numerically and with logarithms

Quadratic functions in standard and vertex form

Quadratic regression

Completing the square

Locating the vertex of a quadratic function and interpreting its meaning

Power, exponential, and logarithmic functions

Logarithmic transformations of data

Estimating the model parameters in power regression

Setting up and solving power equations

Power functions

Combining functions to produce new functions

Laws of exponents and algebra

Setting up and solving power equations

Finding intersection points for power graphs 
Table 12.1. (continued)

\begin{tabular}{ll}
\hline Social Problem & Mathematical Concepts Involved \\
\hline $\begin{array}{l}\text { How quickly can polio be eradicated? } \\
\text { Medical, political, economic, and social } \\
\text { factors }\end{array}$ & $\begin{array}{l}\text { Formulas for polynomial functions } \\
\text { Recognizing polynomial functions from } \\
\text { graphs } \\
\text { Polynomial regression } \\
\text { Locating the zeros of a polynomial } \\
\text { function }\end{array}$ \\
Milestones in the HIV/AIDS pandemic & Patterns in data \\
& Recognizing linear, exponential, and \\
& polynomial functions \\
& Regression \\
& Graphing and interpreting inverses \\
& The horizontal line test \\
& Finding formulas for inverses of linear \\
& and exponential functions \\
\hline
\end{tabular}

quiz questions painted a dim economic picture for the region and highlighted the day-to-day struggles of people who lived on a total income of a few hundred dollars per year, such as obtaining adequate health care. The one exception to this that emerged from the quiz was the nation of Botswana.

The quiz was followed by a short PowerPoint presentation on Botswana highlighting the importance of diamonds for the country's comparatively high per capita gross domestic product (GDP) and the importance of diamond mining for the provision of health care to miners and their families. Also featured, through a series of satellite photographs showing the recession of Botswana's river and lake systems over time, was the fact that Botswana faces a serious shortage of fresh water.

In groups of three or four, students worked on a handout that gave data on the likelihood of Botswana's depleting its water supplies in the next twenty-five years. Students graphed these data and found a linear function to represent them. In a full-class discussion, students considered whether or not a single linear function could accurately represent the data and whether or not a pair of linear functions could do a better job. When students had found a pair of linear functions that worked well, the class was again brought together to consider the question of how to specify the years when each of the two linear functions was appropriate to use, leading to the identification of the mathematical concept of the domain of a function. Students were then asked to use their linear functions to determine the year in which Botswana will definitely run out of fresh water and to decide whether or not the behavior of their linear function accurately represented the situation after that year. Students concluded that once the likelihood reached 100 percent, it should 
remain at that level rather than continuing to rise (as the linear function did). With this, a third, horizontal part was added to the function defined in pieces that the students had created, and the mathematical concept of range (the set of meaningful values generated by a function) was identified.

When the students had finished these calculations, the PowerPoint presentation resumed with a list of historical events from Botswana. One particular point that was greeted with verbal incredulity by students was the fact that until the middle of the twentieth century, it had been legal to hunt the native San people and that the last official license to do so was issued in 1936. This point generated a significant class discussion on the fairness with which the San people had been treated by European colonial powers and continued to be treated by the government of Botswana. This discussion continued with the observation that to maintain its economy, Botswana is under pressure to find new diamond mines but that the most promising lands are those unsuitable for agriculture or urban development that the San have been forced onto. The activity concluded by examining some of the evidence of current government efforts to force the San from potential diamond minesironically, by destroying the San people's fresh water supplies (U.S. Department of State, 2005).

\section{Key Features of the Learning Activities}

Marilyn Frankenstein (1990) pioneered the use of mathematical learning through the study of sociocultural phenomena by undergraduates, developing a series of mathematical learning activities in which students were encouraged to "confront various . . . issues while simultaneously learning basic mathematics" (p. 338). Important principles derived from Frankenstein concerning essential features of the nonmathematical learning activities in this project included the following.

Real situations and real information. Students were expected to spend a significant amount of time and effort learning about the nonmathematical context of the situation. Invented or contrived situations seemed to us unlikely to capture students' imaginations or to present them with an authentic nonmathematical learning experience (du Feu, 2001).

Situations that students might have encountered through news or other media sources but were unlikely to be well informed about. Students' own knowledge or experience was an important touchstone to help the nonmathematical aspects of learning activities gain credibility. As the goals of this course included stimulating both mathematical and nonmathematical learning, it was also important to provide all students (even those who had some exposure to a particular nonmathematical topic) an opportunity to learn something new.

Descriptions of contexts that could generate controversy. An overwhelming priority of many instructors is to eliminate conflicting views or controversies from the classroom (DeCecco and Richards, 1974). However, research in education indicates that properly managed interactions with 
controversial material can help students increase their curiosity, understand other perspectives more accurately, solve problems more effectively, and generate creative ideas (Johnson and Johnson, 1979). An important goal of this instructional model was to help students engage with the material (mathematics and the nonmathematical context) more deeply, and controversy offered a means to achieve this objective.

\section{Evaluating the Model for Integrating Social and Cultural Issues into STEM Learning}

The instructional model described here was tested with a naturalistic experiment (results will be summarized shortly). Students taught with the culturally infused learning activities were compared to other students in the same course who were taught with more conventional materials. Students in the two groups were compared on mathematical performance, general knowledge, and overall success in the course.

Experimental Design. Five separate sections of a precalculus course ( $n=148)$ were taught using a mixture of conventional methods and activities including cultural and social contexts. Twenty-three sections in the same course $(n=593)$ were taught using conventional methods. Two-thirds of students (67 percent) completed questionnaires at the beginning and end of the semester. In addition, all students took three uniform mathematics exams (scored using predefined grading rubrics).

Initial Assessments. Comparing the ACT math scores of the experimental and control groups revealed no significant differences in initial mathematical ability (the mean for the experimental group was 25.17 and for the control group 25.32). The experimental group included slightly higher percentages of female and minority students, although the differences were not statistically significant.

Mathematical Performance. A major concern with this model of STEM instruction is that the large amounts of class time that students spend learning about other cultures could undermine their ability to master the technical content of the course. Two effects have been suggested as important here: the lower amount of mathematical "time on task" experienced by students in the experimental groups (Stallings, 1980; Webb, 1991) and the cognitive "contextual interference effect" (Van Merrienboer, De Croock, and Jelsma, 1997). Students in the control and experimental groups completed exactly the same mathematical exams during the semester (it did not feature any richly contextualized problems), and the exams were all graded in the same way according to predefined rubrics. Repeated measures ANOVA revealed no significant differences in the mean performance of students between the control and experimental groups.

General Knowledge. At the beginning and end of the semester, students completed multiple-choice exams on the topics that were included in the culturally infused activities. At the beginning of the semester, the differ- 
ence in the percentage of questions answered correctly by both groups was an insignificant 0.14 percent. By the end of the semester, the percentage of correct responses from the experimental group exceeded that of the control group by a significant 11.9 percent $(p<.05)$.

Success in the Course. For the purposes of this experiment, success in the course was defined as course completion with a grade of $C$ minus or higher. The final grades in the precalculus course were determined by the students' scores on the uniform exams and modified up or down by instructors. The percentage of unsuccessful students in the experimental group was 15.4 percent, which was significantly $(p<.05)$ lower than the 22.9 percent of unsuccessful students in the control group.

\section{Impact on Students}

Although the statistics indicate that the use of this instructional model increased students' general knowledge without sacrificing mathematical performance, they do not reveal the impact of the activities on individual students. Two anecdotes from the course may indicate some of the ways in which students were affected by the course in less easily quantitatively measured ways.

The first is an unsolicited e-mail received by one of the instructors who taught using these learning activities. The text of the e-mail speaks for itself:

I wanted to thank you for all your help throughout the semester. I am amazed at how much I was able to learn despite the fact that I took precalculus in high school. Your class was always interesting, and I am still amazed at the things that I learned pertaining to the world at large, and not solely mathematics. I never thought that I would be informed about so many significant and often disturbing issues plaguing our world in a math class... I hope that you already were aware that your students find your teaching techniques refreshingly innovative and helpful. If you weren't, I hope you know now.

The second anecdote concerns the reaction of a group of students from another class that used these learning activities. These students felt so strongly that they wanted to do something concrete and real that they (with the help of their instructors) created a scheme to earn money from sponsors whenever they did well on a math quiz. The money that was collected (over $\$ 300$ by the end of the semester) was donated to a charity that worked on the kinds of social and health care problems that the students had learned about.

\section{Summary}

This chapter described an instructional model for infusing social and cultural learning into a technical course. It also included evidence to demonstrate that STEM courses can be infused with social and cultural without negatively affecting STEM learning. Learning mathematics with substantial 
amounts of social and cultural information did not detract from mathematical learning. Furthermore, as noted by Astin (1993), infusing courses with social and cultural content can lead to cognitive learning gains (knowledge of global health care issues). Students in the experimental group were more likely to complete the course and less likely to end the semester with an unacceptable grade than students in the control group. As the experimental group contained a higher number of female students and students from minority groups, one possibility is that the instructional methods and content used here made the mathematics in the class more appealing or more accessible to students who might otherwise have disappeared from or failed the class (Seymour and Hewitt, 2000).

\section{References}

Alper, L., Fendel, D., Fraser, S., and Resek, D. "Problem-Based Mathematics: Not Just for the College-Bound." Educational Leadership, 1996, 53(5), 18-21.

Astin, A. W. What Matters in College? Four Critical Years Revisited. San Francisco: JosseyBass, 1993.

Bookman, J., and Friedman, C. P. "A Comparison of the Problem-Solving Performance of Students in Lab-Based and Traditional Calculus." In E. Dubinsky, A. H. Schoenfeld, and J. Kaput (eds.), Research in Collegiate Mathematics Education, Vol. 1. Providence, R.I.: American Mathematical Society, 1994.

Carter, C. S., and Brickhouse, N. W. "What Makes Chemistry Difficult? Alternate Perceptions." Journal of Chemical Education, 1989, 66(3), 223-225.

Cooper, B. "Testing National Curriculum Mathematics: Some Critical Comments on the Treatment of 'Real' Contexts for Mathematics." Curriculum Journal, 1992, 3(3), 231-243.

De Bock, D., and others. "Do Realistic Contexts and Graphical Representations Always Have a Beneficial Impact on Students' Performance? Negative Evidence from a Study on Modeling Non-Linear Geometry Problems." Learning and Instruction, 2003, 13(4), 441-463.

DeCecco, J., and Richards, A. Growing Pains: The Uses of School Conflict. New York: Aberdeen Press, 1974.

du Feu, C. "Naming and Shaming." Mathematics in School, 2001, 30(3), 2-8.

English, L. D., and Halford, G. S. Mathematics Education: Models and Processes. Mahwah, N.J.: Erlbaum, 1995.

Forman, S. L., and Steen, L. A. "Beyond Eighth Grade: Functional Mathematics for Life and Work." In M. J. Burke and F. R. Curcio (eds.), Learning Mathematics for a New Century. Reston, Va.: National Council of Teachers of Mathematics, 2000.

Frankenstein, M. "Incorporating Race, Gender, and Class Issues into a Critical Mathematics Literacy Curriculum." Journal of Negro Education, 1990, 59(3), 336-347.

Ganter, S. L. (ed.). Calculus Renewal: Issues for Undergraduate Mathematics Education in the Next Decade. New York: Kluwer Academic/Plenum, 2000.

Ganter, S. L. Changing Calculus: A Report on Evaluation Efforts and National Impact from 1988-1998. MAA Notes no. 56. Washington, D.C.: Mathematical Association of America, 2001.

Graesser, A. C., Person, N. K., and Hu, X. "Improving Comprehension Through Discourse Processing." In D. F. Halpern and M. D. Hakel (eds.), Applying the Science of Learning to University Teaching and Beyond. New Directions in Teaching and Learning, no. 89. San Francisco: Jossey Bass, 2002.

Hauser, M. "Parental Guidance Required." In J. Brockman (ed.), Intelligent Thought. New York: Vintage Books, 2006. 
Hurley, J. F., Koehn, U., and Ganter, S. L. "Effects of Calculus Reform: Local and National." American Mathematical Monthly, 1999, 106(9), 800-811.

Johnson, D. W., and Johnson, R. T. "Conflict in the Classroom: Controversy and Learning." Review of Educational Research, 1979, 49(1), 51-70.

Lutzer, D. J., Maxwell, J. W., and Rodi, S. B. Statistical Abstract of Undergraduate Programs in the Mathematical Sciences in the United States. Providence, R.I.: American Mathematical Society, 2002.

Miller, A. T. "The Multicultural Lab: Diversity Issues in STEM Classes." In M. Ouellett (ed.), Teaching Inclusively. Stillwater, Okla.: New Forums Press, 2005.

National Survey of Student Engagement. Student Engagement: Pathways to Collegiate Success. Bloomington: Indiana University Center for Postsecondary Research, 2004.

Nix, G. A., Ryan, R. M., Manly, J. B., and Deci, E. L. "Revitalization Through SelfRegulation: The Effects of Autonomous and Controlled Motivation on Happiness and Vitality." Journal of Experimental Social Psychology, 1999, 35(2), 266-284.

Pollack, H. O. "On Mathematics Application and Real Problem Solving." School Science and Mathematics, 1978, 78(3), 232-239.

Schiefele, U., and Csikszentmihalyi, M. "Motivation and Ability as Factors in Mathematics Experience and Achievement." Journal for Research in Mathematics Education, 1995, 26(2), 163-181.

Selden, J., Mason, A., and Selden, A. "Can Average Calculus Students Solve Nonroutine Problems?" Journal of Mathematical Behavior, 1989, 8(1), 45-50.

Seymour, E., and Hewitt, N. M. Talking About Leaving. Why Undergraduates Leave the Sciences. Boulder, Colo.: Westview Press, 2000.

Smith, D. A. "Renewal in Collegiate Mathematics Education." Documenta Mathematica, 1998, Extra Volume(3), 777-786.

Stallings, J. "Allocated Academic Learning Time Revisited, or Beyond Time on Task." Educational Researcher, 1980, 9(11), 11-16.

U.S. Department of State. "Botswana: Country Reports on Human Rights Practices, 2004." Feb. 28, 2005. http://www.state.gov/g/drl/rls/hrrpt/2004/41589.htm. Retrieved May 31, 2007.

Van Merrienboer, J.J.G., De Croock, M.B.M., and Jelsma, O. "The Transfer Paradox: Effects of Contextual Interference on Retention and Transfer Performance of a Complex Cognitive Skill." Perceptual and Motor Skills, 1997, 84(1), 784-786.

Walkerdine, V. The Mastery of Reason. London: Routledge, 1988.

Webb, N. M. "Task-Related Verbal Interaction and Mathematics Learning in Small Groups." Journal for Research in Mathematics Education, 1991, 22(5), 366-389.

Wiest, L. "Multicultural Mathematics Instruction: Approaches and Resources." Teaching Children Mathematics, 2002, 9(1), 49-50.

Zoller, U. "Students' Misunderstandings and Misconceptions in College Freshmen Chemistry (General and Organic)." Journal of Research in Science Teaching, 1990, 27(9), 1053-1065.

DALE WINTER is an assistant professor in the Department of Mathematics at the University of Michigan, where he codirects the freshman-sophomore program in mathematics. 